\title{
Towards distribution energy management systems: Maximising renewable DG
}

DOI:

10.1049/cp.2013.1231

Link to publication record in Manchester Research Explorer

Citation for published version (APA):

Alnaser, S. W., \& Ochoa, L. F. (2013). Towards distribution energy management systems: Maximising renewable DG. In IET Conference Publications/IET Conf Publ (Vol. 2013) https://doi.org/10.1049/cp.2013.1231

\section{Published in:}

IET Conference Publications|IET Conf Publ

\section{Citing this paper}

Please note that where the full-text provided on Manchester Research Explorer is the Author Accepted Manuscript or Proof version this may differ from the final Published version. If citing, it is advised that you check and use the publisher's definitive version.

\section{General rights}

Copyright and moral rights for the publications made accessible in the Research Explorer are retained by the authors and/or other copyright owners and it is a condition of accessing publications that users recognise and abide by the legal requirements associated with these rights.

\section{Takedown policy}

If you believe that this document breaches copyright please refer to the University of Manchester's Takedown Procedures [http://man.ac.uk/04Y6Bo] or contact uml.scholarlycommunications@manchester.ac.uk providing relevant details, so we can investigate your claim.

\section{OPEN ACCESS}




\section{TOWARDS DISTRIBUTION ENERGY MANAGEMENT SYSTEMS: MAXIMISING RENEWABLE DG}

\author{
Sahban W ALNASER \\ University of Manchester - UK \\ Sahban.alnaser@postgrad.manchester.ac.uk
}

\author{
Luis F OCHOA \\ University of Manchester - UK \\ luis_ochoa@ieee.org
}

\begin{abstract}
Actively managing network constraints in real time may allow Distribution Network Operators (DNOs) to connect greater volume of renewable DG without the need of expensive reinforcements. A distribution Energy Management System (EMS) is proposed to maximise the harvesting of renewable DG and accelerate the transition towards low carbon network. This is based on optimally control the operation of the voltage control devices and DG power factor, using as last resort DG curtailment. The proposed EMS is applied to a real-life UK MV network from the North West of England. The results show that the proposed EMS is capable of managing the network within voltage and thermal capacity limits whilst minimizing DG curtailment.
\end{abstract}

\section{INTRODUCTION}

The increasing levels of renewable Distributed Generation (DG) on the traditionally passive distribution network pose significant technical and economic challenges on the Distribution Network Operators (DNOs). In particular, the variability of wind generation and its non-coincidental pattern with demand may create a reverse current flowing upstream that cause a deviation in the voltage levels above the statutory limits and violate the thermal ratings of the network equipments. To alleviate these issues, most DNOs consider the worst case condition (i.e., maximum generation and minimum demand) which is statistically rarely to occur. This "fit and forget" connection approach may considerably restrict the potential hosting capacity of the distribution network and may increase the capital cost to be paid by the DG developer. Consequently, to effectively integrate more renewable DG a more intelligent management of the network is required.

The regulatory incentive mechanisms in the UK is designed to encourage DNOs to connect greater volumes of DG and to defer the required capital expenditure (i.e., network reinforcements) when technically possible [1]. Consequently, DNOs are motivated to explore efficient and flexible solutions for the connection of DG. In the last few years, a few DNOs have implemented Active Network Management (ANM) schemes to actively control the real power output of wind turbines and curtail their power production to reach acceptable network operating margins (i.e., thermal and voltage limits) [2].

Although energy harvesting is not the main interest of DNOs in countries with unbundling rules, DG curtailment should be restricted as much as possible to accelerate the transition to a low carbon economy. In order to allow more power injection than when only curtailment is applied, the Coordinated Voltage Control (CVC) of the On Load Tap Changers (OLTCs) and active management of the DG power factor can be utilised to mitigate voltage excursion.

This paper presents a comprehensive distribution Energy Management System (EMS) platform aimed at maximising energy harvesting from renewable wind sources whilst managing network constraints (i.e., voltage rise and thermal overloads). A centralised AC Optimal Power Flow (OPF) (i.e., a non-linear programming problem) to produce the optimal set points for the active elements is adopted [3]. This AC OPF is tailored to comply with the existing connection agreements that might allow some DG plants to deliver power up to its rated capacity (i.e., firm connections). As well as, for OLTCs that are locally controlled with respect to the measurements at the regulated terminal, the values of the tap positions are included in the optimization engine as fixed parameters

\section{DISTRIBUTION EMS}

The proposed distribution EMS platform is shown in Fig. 1. Pseudo real-time measurements, to be in practice managed by a SCADA system, are obtained from timeseries simulations run by a distribution network modelled in OpenDSS [4]. Network elements are monitored each control cycle in order to identify branches (i.e., lines or transformers) exceeding the thermal loading threshold or nodes with voltages beyond the voltage threshold limits.

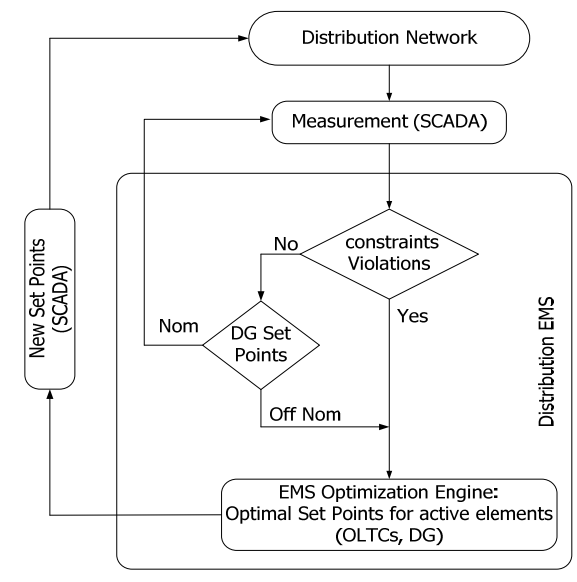

Fig 1. Architecture of the proposed Distribution EMS. 
The EMS AC OPF-based optimization engine, implemented in the modelling language AIMMS [5], finds the best set points for the available controllable resources (i.e., OLTCs, DG power factor, and DG curtailment) upon the violation of constraints (or the existence of curtailment). These new set points will be used throughout the following control cycle. As a proxy of minimizing DG curtailment, the AC OPF formulation has an objective to maximize the total active power of the controllable DG plants (set G, indexed by g),

$$
\max \sum_{g \in G} P_{g}
$$

\section{CASE STUDY: REAL LIFE 33KV-NETWORK}

The proposed distribution EMS is applied to a real-life UK MV network from the North West of England in order to assess its effectiveness in managing renewable DG.

\section{Test Network}

The electrical network characteristics are converted from the utility's power system analysis software (IPSA) to OpenDSS. The single line representation of the network is given in Fig 2. The $33 \mathrm{kV}$-feeders of the test network are supplied by two 63MVA $132 / 33 \mathrm{kV}$ power transformers at the Bulk Supply Point (BSP). The voltage of the $33 \mathrm{kV}$ system is regulated by the OLTCs in the BSP using standard regulation range of $+10 \%$ to $-20 \%$, typically in 18 steps of $1.67 \%$ with a voltage dead-band setting of $\pm 2 \%$ and a time delay of 90 s. Similarly, the primary substations $33 / 11 \mathrm{kV}$ are equipped with OLTCs to regulate the voltage to a pre-defined target of 1.0 p.u. at the $11 \mathrm{kV}$ terminal. The regulation range for the OLTCs in the primary substations is $-17.16 \%$ to $+5.72 \%$ in 16 steps of a step of $1.43 \%$ (using a dead-band of $\pm 1.5 \%$ and a time delay of $120 \mathrm{~s}$ ).

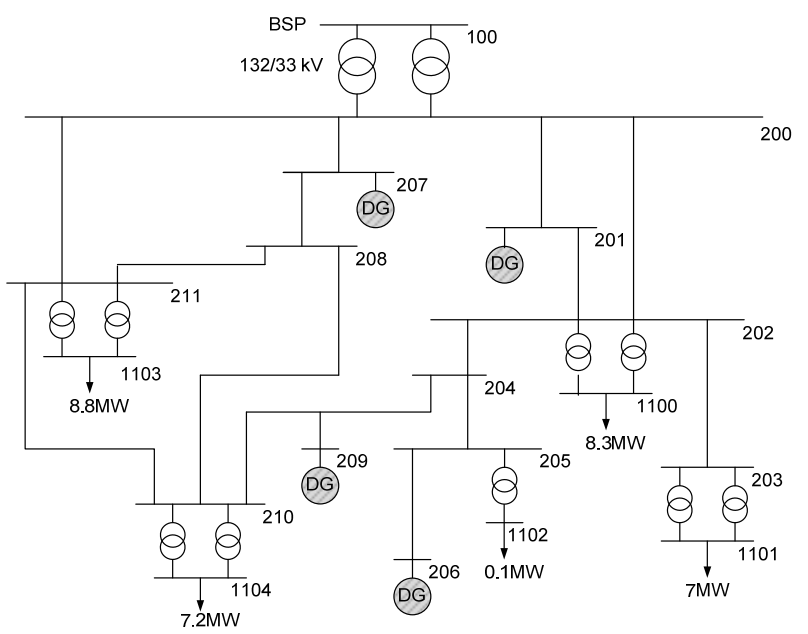

Fig 2. Real-life UK MV network from the North West of England.
The load shapes for the demands in the network are generated based on; the annual substation peak demand and the number of customers in different metering classes (e.g., domestic unrestricted, domestic with two tariff rates, small non-domestic) for each primary substation as well as the normalized half-hourly profiles classes for the UK customers in the North West of England. Since the vast majority of consumers are adopting domestic unrestricted tariff class, the resulting load profiles at the primary substations, in general, follow the same pattern. The maximum and the minimum demands of the network are 31 and $15 \mathrm{MW}$, respectively.

The network accommodates four DG with firm connection agreement at buses 201, 206, 207 and 209 with capacities of $9.1,10.6,7.5$ and $12 \mathrm{MW}$, respectively.

The multi-period AC optimal power flow planning tool, that was proposed in [3], is applied to calculate the maximum additional DG capacity that can be connected to the test network at the same locations of the existing firm DG with the employment of a range of ANM schemes (OLTCs, DG Pf control, and DG Energy curtailment). It was found that an extra $52 \mathrm{MW}$ can be connected to the network at the buses 201, 206, 207, and 209 with capacities of 4, 6.5, 15, and 26.5 MW, respectively. All the generators are capable of operating with power factors between 0.95 inductive and capacitive according to UK requirements [14]. It is assumed that all the DG (firm and the new) in the network has the same wind resource. The average demand and the wind profiles for $1^{\text {st }}$ February 2010 are shown in Fig. 3.

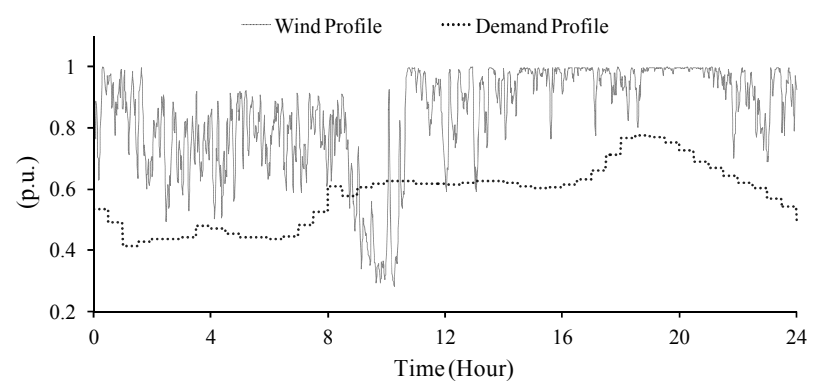

Fig 3. Normalized wind and demand profile in the $1^{\text {st }}$ day of February 2010.

\section{Business as Usual Operation}

To examine the benefits from the proposed distribution EMS in managing network constraints, the business as usual operation (i.e., no active management) is compared with different active network solutions. Given that simulations are carried out with one minute resolution, the analyzed period is limited to one day of the first week of February 2010. 
During the worst case scenario, the wind farms create a significant reverse power flow through the lines in the network. The maximum thermal violations occur at line 200-201 (main line) that would exceed its thermal limits (17 MVA) by $21 \%$. In addition, the voltage at bus 205 exceeds the upper statutory limits in the UK $(6 \%)$ and reaches 1.09 p.u.. The voltage excursions at this bus occur during $23 \%$ of the analysed week which clearly shows that the voltage profiles do not comply with the European standard EN50160. This standard states that during an observation period of a week, $95 \%$ of the voltage magnitude measurements should be within the statutory limits. It should be mentioned that a slight modifications are applied to the EN50160 standard such that the voltage variation limits is modified to $( \pm 6 \%)$ as well as the evaluation is carried over a fixed interval of one minute instead of 10-minute.

\section{EMS-Curtailment only}

Here, the proposed ac OPF-based distribution EMS is continuously monitoring network elements and controlling (if necessary) the output of DG plants every five minutes. The voltage thresholds is set to $90 \%$ below the upper voltage limit (1.054 p.u.) as well as the lineflow threshold is set to $90 \%$ of the thermal capacity of the network elements (i.e., transformers and lines). When the measured values exceed these thresholds, control scheme is initiated and corrective action is applied. To illustrate the operation of the curtailment-only EMS, the loading of line 200-201, the voltage profile at bus 205 and the set points of three wind farms (that affect the loading of the line 200-201) are all shown in Fig. 4 for the same hour in February.

It can be seen that in minute 1 , the controller is activated to solve for thermal issue. Based on the optimisation engine, the EMS sends a control signal to the wind farms in order to pitch the turbines' blades in a way that the set points are now 57\%, 51\% for the wind farms 201 and 206, respectively. Although this setting will be kept until the next control cycle, the one-minute resolution simulations show the corresponding response. At minute 5 there is no constraint violation the EMS will trigger the optimization to find new set points to maximise the total active power of the controllable DG units given that curtailment has been applied to the wind farms. The total output of the DG plants is indeed partially improved at minute 6 by $1.3 \mathrm{MW}$. In minute 15 , the EMS reacts to voltage issue at bus 205 and deeply ramp down the set point for DG at bus 206 to a level of $29 \%$. This process of monitoring and updating the wind farm's set point accordingly is carried out at each control cycle.

With EMS-curtailment scheme, the voltage profile at bus 205 maintains within the statutory limits for $(99.99 \%)$ of and complies with the EN50160 standard.
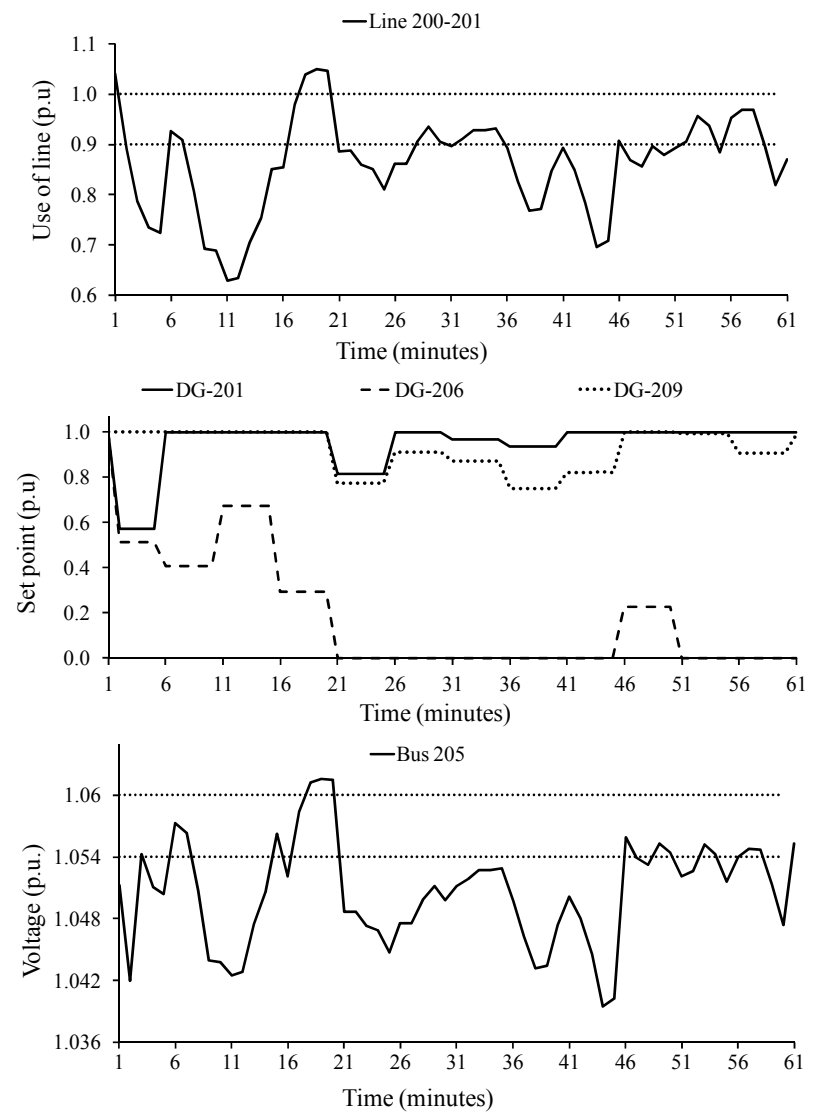

Fig 4. (Top) Use of line 200-201 p.u., (middle) Voltage profile at bus 205 p.u. and (bottom) set points of DG(201,206 and 209 ) after applying curtailment only.

\section{EMS-Curtailment, CVC and Power Factor}

The active management of the OLTC in the BSP and the power factor of the wind farms can alleviate voltage excursions and decrease the use of curtailment. It can be seen from Fig 5. that the taps of the OLTC are increased and the wind farm at bus 206 operates at inductive power factor (mostly close to 0.95 ) in order to minimize curtailment whilst maintaining the voltage at bus 205 below the upper statutory limit. Crucially, the DG at bus 206 is given a set point around $25 \%$ during the minutes (22-44) allowing power injection instead of being fully curtailed when only applying curtailment for the same period. For instance, in minute 21 the tap in the BSP is increased to 1.0501 and the power factor is set to $(-0.95$ inductive) and the DG is given a set point of $17 \%$.

It can be observed that at minute 45 , the optimizer decides to raise the wind farm's set point based on the voltage and the use of the line (within limits). However, in the next minute the wind speed increases resulting in thermal issues beyond the limit. This error is due to the adopted persistence forecasting model which considers that the wind resource and demand remain the same from one cycle to the next one. 

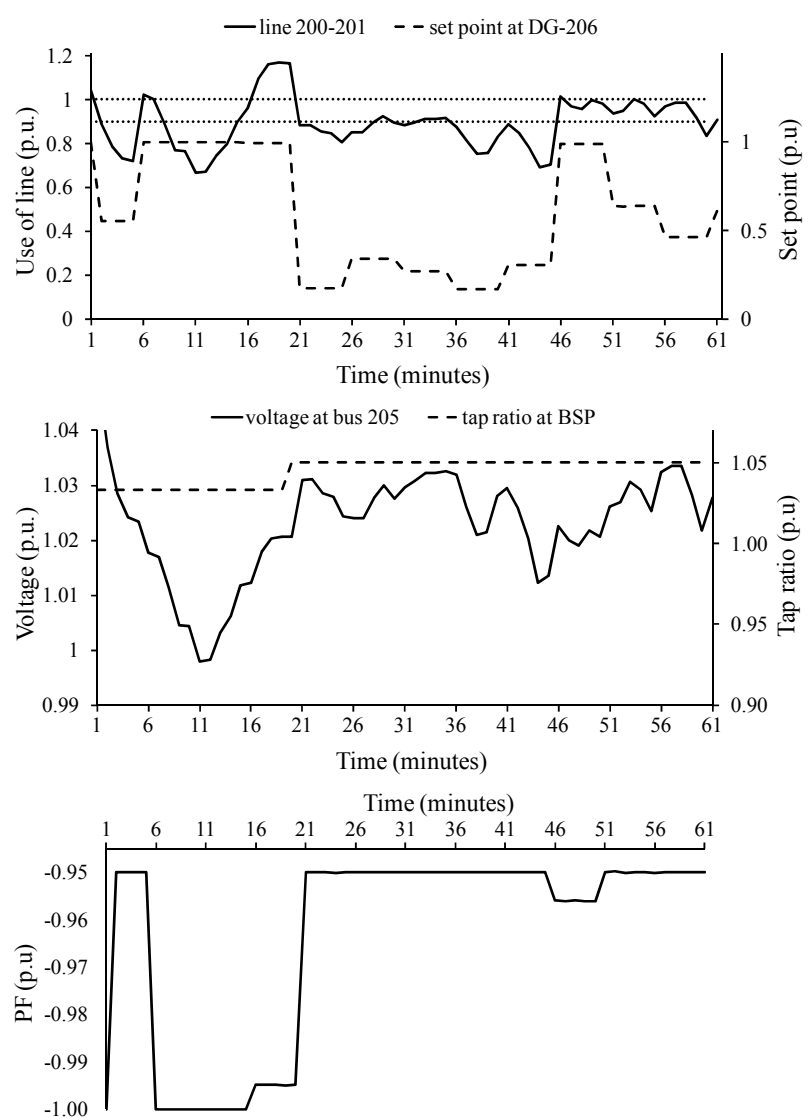

Fig 5. (Top) Use of line 200-201 p.u. (left), and set point for DG-206 (right), (middle) Voltage profile at bus 205 p.u. (left) and tap ratio at BSP (right) and (bottom) reactive power for DG-206 after applying curtailment, $\mathrm{CVC}$ and PF.

The use of short control cycles allow closely following wind variability and most likely preventing the impacts of substantial changes in generation. This is can be clearly seen in Fig 6. That the power flow profile in line (200201) when applying a control cycle length of 1-minute. However, it should be mentioned that the granularity of monitoring and controlling the operating margins in network is strictly limited by the required time for the data acquisition and the processing times of the optimizer as well the communication channel characteristics (e.g., latency, bandwidth).

\section{Energy Harvesting}

For the first week of February 2010, the application of the full EMS leads to $2.87 \mathrm{GWh}$ of production, which is $6.7 \%$ above the curtailment scheme alone.

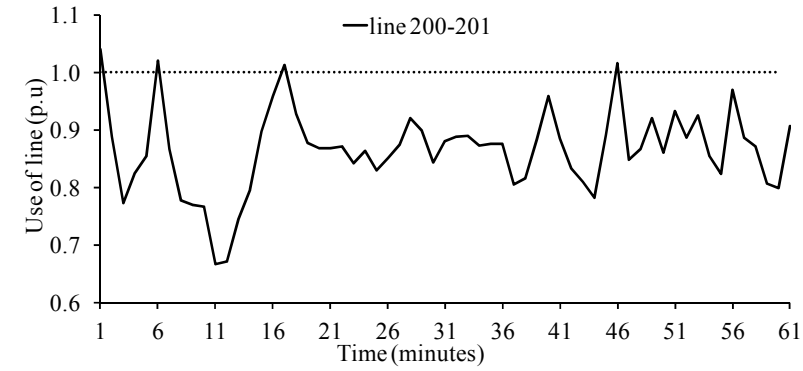

Fig 6. Use of line 200-201 p.u. after applying curtailment, CVC and PF with1 minute control cycle.

\section{CONCLUSIONS}

The proposed Distribution EMS is applied to a real-life UK MV network from the North West of England considering multiple generators and OLTCs. The results show that the thermal and voltage constraints in the network are effectively managed in real time and high volume of DG capacity can be connected to the network. The active management of OLTCs and DG power factor can alleviate voltage rise issues and minimize energy curtailment. The benefit of adopting higher sampling rate in the proposed EMS in order to closely follow the network behaviour is presented. This work will be developed to cater for the uncertainties in the wind profile and with applying different control cycles.

\section{REFERENCES}

[1] Office of Gas and Electricity Markets (Ofgem), "Electricity distribution price control review Final proposals - Incentives and Obligations," Dec. 2009.

[2] R.A.F. Currie, G.W. Ault, C.E.T. Foote, and J.R. McDonald, 2007, "Active power-flow management utilising operating margins for the increased connection of distributed generation", IET Proceedings Generation, Transmission \& Distribution. vol. 1, 197-202.

[3] L.F. Ochoa, C. Dent, and G.P. Harrison, 2010, "Distribution network capacity assessment: Variable DG and active networks", IEEE Trans. on Power Systems. vol. 25, 87-95.

[4] Open Distribution System Simulator OpenDSS. [Online]. Available: http://sourceforge.net/apps/mediawiki/electricds $\underline{\mathrm{S}}$

[5] J. Bisschop and M. Roelofs, "AIMMS - The user's guide," Paragon Decision Technology, 2006. 